\title{
When consent is unbearable: an alternative case analysis
}

\author{
George J Agich Departments of Medical Humanities and Psychiatry, Southern Illinois University, \\ Springfield, Illinois
}

\begin{abstract}
Dr Agich takes up a previous difficult case related by Dr Kottow in an earlier issue of the Journal. ${ }^{1}$ He analyses the three ethical problems as presented in the case and offers his own opinion of it as well as his own conclusions with regard to the medical ethical aspects of it. Unlike Dr Kottow, Dr Agich's reading of the case indicates that the application of the principle of informed consent does not rule out ethical decisions for the physician, but emphasises the relevance of ethical analysis beyond the issue of informed consent.
\end{abstract}

In an earlier issue of this fournal, Dr Kottow ${ }^{1}$ has shared with us a difficult case in which the attending physician chose to withhold information from a patient diagnosed as having adenocarcinoma of the lacrimal gland. Three ethical problems are present according to Dr Kottow:

I) Information was withheld from the patient.

2) Medical decisions were taken without his consent.

3) A conservative management was chosen against the recommendation of the pathologist and of current medical thought.

Of these three ethical problems, Dr Kottow rightly sees informed consent as central. But Dr Kottow's analysis of this case, particularly of informed consent, is less than satisfying.

The decision to bypass informed consent was based upon two considerations, namely the options (elective blindness and possible death versus retained vision and possible death) were equally discouraging and the medical opinion regarding treatment was equivocal. For these reasons the physician chose not to inform his patient. Because the case confronts the physician with the 'unusual circumstance' of having to chose between two equally hopeless alternatives, the conclusion is drawn by Dr Kottow that 'had the physician in this case abided by the basic rule that a person is due full information about his disease, there could have been no ethical issue at stake'. Corollary to this conclusion is the view that 'medical ethics are only applicable to situations and issues where the physician is fully involved in the act of decisionmaking'.

I want to disagree with Dr Kottow's analysis of this case as well as with his conclusion regarding medical ethics. Even if the principle of informed consent ruled out further ethical difficulty for the physician, there are still ethical considerations regarding the handling of the case which fah within the sphere of physician decision-making bu which are not adequately discussed. Unlike $\mathrm{D}$ Kottow my reading of this case indicates that theprinciple of informed consent does not rule ouf ethics for the physician, but precisely emphasises the relevance of ethical analysis beyond the issue of informed consent.

About what was the patient not informed? The patient was told that a malignant tumour was removed; he was scheduled for regular follow-ub visits which persisted for two years. The patient was not told that the malignant tumour removed was likely to metastasise and that in a large series of patients suffering from adenocarcinoma of the lacrimal gland no patient, irrespective of treatmento was alive and free of recurrence and/or metastases In other words, the patient was not told that he ha\& a fatal, incurable disease. According to Dr Kottow medical experience regarding adenocarcinoma was inadequate to allow for a clear appraisal of the diagnosis and prognosis of the disease. So, the decision to withhold information had to be made in terms of other considerations. It would seem that Dr Kottow's justification for withholding informa? tion should include a careful analysis of these considerations. Surprisingly, however, they remain implicit and unanalysed. Nevertheless, the following would be a fair assessment of the facts as presented?

The patient, an unskilled farmhand was intell gent and cooperative and would have been able t grasp the dimensions of his medical problem but 'he was in no position to change any of the factoris which govern his social and economic life'. Th\& information regarding the life-threatening conditiof which he had would certainly cause psychologicat and emotional stress, "but could not be considered information he could usefully elaborate to changs his or his family's material circumstances'. Two further facts are given: the family was unknown to the physician and the country where the probleri occurred lacked social, economic or rehabilitationglf facilities.

The values appealed to in this case thus relate to the economic and material circumstances of the patient. Because the medical information which the physician possessed could not be used in a was 
which affected the family fortunes, the patient was not informed, the implicit principle being that there is a direct relationship between the claim which a patient can make to full disclosure of information and the degree of control of the factors governing his economic and social life. But such an alternative to the principle of informed consent is clearly objectionable.

First, it makes the principle of informed consent depend upon a sphere of goods. Values, e.g. of freedom, compassion, and love, are thereby reduced to the domain of material goods. ${ }^{2}$ Second, the decision made cannot be justified even on paternalistic grounds. Since the physician did not know the family and its precise circumstances, his decision was premised on ignorance. Thus, he could not be said to be acting in the best interests of the family and his patient, since he did not know those interests.

Not only did the physician not consider (perhaps because he was simply ignorant) the economic, social and emotional resources of the patient's family, he interpreted these resources in the Western liberal tradition of social services. So, another factor which is alleged to be relevant in the decision is the fact that the country where this problem occurred did not offer social, economic, or rehabilitational facilities. But depending on the actual country (which is not identified), this may well represent a foreign cultural bias which reflects the values implicit in the physician's own conception of support services rather than a fair assessment of the patient's circumstances.

All of the value judgements which Kottow uses to support the decision not to inform the patient are open to question. But perhaps it will be argued that there was another, more significant reason for not informing the patient, namely that information could yet be offered when the lesion recurred or the appearance of metastases supported the expected fatal outcome. This kind of consideration leads to the second point regarding the ethics of physician autonomy vis à vis patient autonomy.

The case is said to be difficult because the physician has little to offer except two hopeless alternatives. Kottow argues that the hopelessness was the ground for withholding information and for adopting a 'paternalistic' rather than 'contractual' relationship. But in making this move, Dr Kottow seems to confuse two different kinds of physicianpatient relationship: treatment relationship and course of treatment relationship.

In the treatment relationship there are three models: activity-passivity, guidance-cooperation, and mutual participation in which the degree of physician autonomy vis à vis patient autonomy changes. ${ }^{3}$ The shift from one model to another depends largely upon the nature of the therapy in question. The course of treatment relationship is characterised by two points:
I) The physician chooses the patient's course of treatment until either terminates the relationship;

2) The physician proposes, the patient decides. ${ }^{4}$

Given the importance of informed consent in current medical ethical thought, a point which Kottow readily concedes, it should be clear that the course of treatment relationship now preferred is the second, namely the physician proposes and the patient decides (i.e., informed consent). The legal and moral justification for this position is well-documented throughout the literature. So, if we grant the general validity of the principle of informed consent, namely that except in emergencies the competent adult patient must decide whether or not he is to accept any proposed treatment (and Dr Kottow nowhere explicitly challenges this principle), it is inconsistent to sanction a physician's withholding information essential to the patient's forming an intelligent judgement on the question even when the alternatives appear 'hopeless'.

What is significant about this case is the fact that the physician chose not to offer the patient radical surgery, i.e. chose not to offer the activity-passivity treatment model, but instead chose to adopt a different course of treatment, namely one inconsistent with the principle of informed consent. The crucial question in this regard is how is this decision justified?

From our analysis of the values implicit in the interpretation of the facts of this case, it is not clear that this shift in course of treatment relationship is justified. For instance, were the values appealed to fair to the patient and the patient's family? The physician chose not to offer radical surgery (the activity-passivity treatment model), but instead offered a guidance-cooperation treatment model as evidenced by the treatment plan of long term follow-up. But, the treatment model being chosen, guidance-cooperation itself presupposes patient autonomy, autonomy which is denied by the shift from an informed consent course of treatment relationship to a paternalistic one.

In other words, by not informing, the physician failed to respect the patient's autonomy; in not respecting patient autonomy, the physician in principle prohibited the patient from participating as a moral and personal agent in the treatment process, while at the same time requiring the patient to so participate (guidance-cooperation). Hence, deception was necessarily required throughout the course of follow-up treatment and constitutes another relevant factor in this case.

Finally, because Dr Kottow confuses the course of treatment and the treatment relationship, he draws an unfortunate lesson from this case, namely that if the decision is put in the hands of the patient, the physician is relieved from any ethical dilemma.' This conclusion is unfortunate because it obscures the ethical dimensions of the course of treatment in 
which deception is continuously involved. Rather than presenting a case which justifies withholding information, the case thus emphasises the validity of the principle of informed consent as a prerequisite to the physician-patient relationship, and, in doing so, highlights poignant value dimensions of that relationship.

\section{References}

${ }^{1}$ Kottow, Michael (1978). When consent is unbearable: a case report, fournal of medical ethics, 4, 78-80.
2Scheler, Max (1973). Formalism in Bthics and Non? Formal Ethics of Value, Manfred S Frings ant Roger L Funk, tr. Bvanston: Northwester University Press.

${ }^{3}$ Szasz, Thomas $S$ and Hollender, Mark (1956). The basic models of the doctor-patient relationship A.M.A. Archives of internal medicine, 97, 585-92.

'Donagan, Alan (1977). Informed consent in therapy an experimentation, fournal of medicine and philosophy? 2, 307-29. 